\title{
Science worth fighting for
}

\author{
Against a backdrop of political upheaval and polarization, European science continues to be a bright spot, at least
} for now.

$\mathrm{O}$ ne hopes to hit a consensual note when stating that the past couple of years have been politically turbulent for many European countries. While the financial crash of 2008 resulted in immediate social and political turmoil in some countries, the backlash to nearly a decade of economic austerity took a little longer to become manifest in others.

Britain's shock vote to leave the European Union nearly two years ago, while clearly a result of many factors, can be viewed as one notable example of this delayed reaction. But it has since been followed by a flurry of polarizing elections around the continent: political movements campaigning on hitherto unthinkably radical platforms did well, and in many cases won at the cost of the traditional, pro-EU social democratic and centre-right parties that - rightly or wrongly - have become associated with the ugly side of free trade and globalization. Throw in a few demagogues able to tap into the mood of public discontent and a news cycle that, in addition to creating a deafening amount of noise, also feeds polarization through the pernicious echo chamber effect of social media, and it is hard to avoid the conclusion that the leaves have started to stir.

For many scientists based in the UK, the sense of dislocation and unease is compounded by the fact that, in addition to following a witless policy of disengagement from its closest political and economic partners, their country of residence has also recently undergone a number of significant reforms to its higher education sector: the establishment of UKRI (UK Research and Innovation), a new 'super-agency' that brings together the activities of nine research councils in overseeing more than $£ 6$ billion ( $€ 6.9$ billion) of research funding per year, and an overhaul to the universities' pension scheme that was contentious enough to trigger national strikes. Anecdotally at least, it is common to hear complaints that these market-driven reforms have gone too far, and many look longingly at institutions in Germany, Switzerland and other northern European countries that undoubtedly innovate and, for want of a better description, trust scientists with money.

If the latest-round European Research Council (ERC) advanced grants are

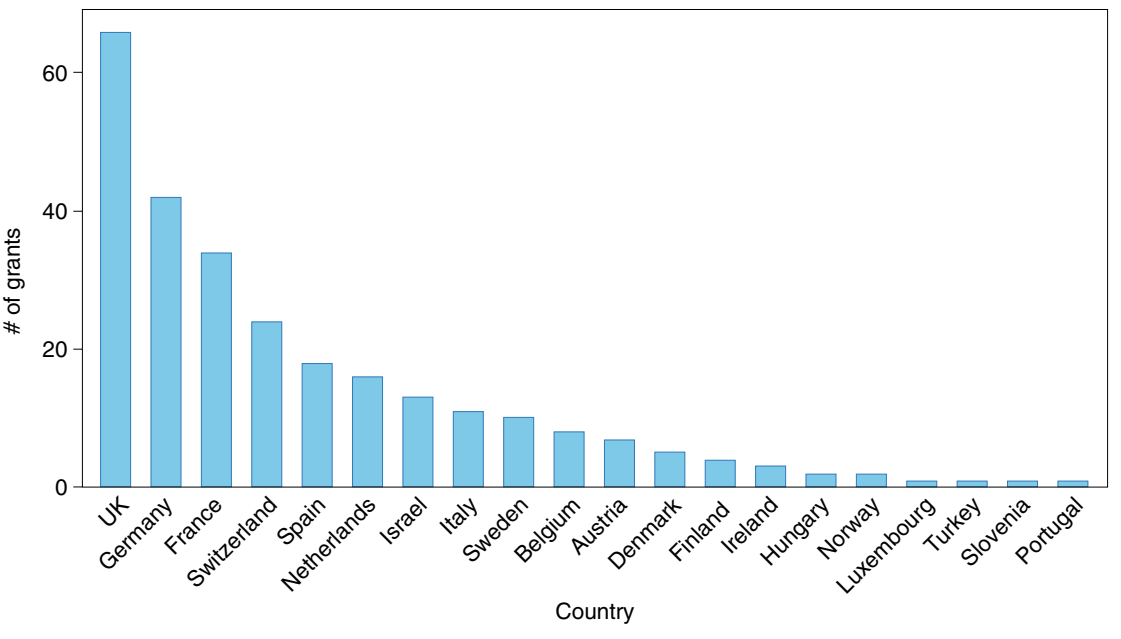

Fig. 1 | ERC Advanced Grants 2017 by country of host institution. Credit: data courtesy of the ERC

anything to go by, perhaps there is scope for a little more optimism. Whichever way one cuts it, UK-based investigators performed excellently, amassing 66 out of a total of 269 grants worth over $€ 653$ million (Fig. 1). Crucially, however, over a third of the grantees based in the UK are not UK nationals. This not only reflects the cosmopolitan nature of the British research environment and highlights the value of freedom of movement across the EU and its associated countries, it also shows a country that is closely integrated with the rest of Europe. It is also worth noting that in Switzerland, by far the best ERC performer on a per capita basis, half the number of grantees weren't Swiss, whereas in Italy, a relative laggard according to the same criterion, all the grantees were Italian. Excellence and mobility really do go hand in hand.

Of course one shouldn't read too much into these results - they don't directly inform us on the local research conditions away from the labs lucky enough to be awarded ERC grants, and focusing on the top end of quality spectrum leaves the door open to the criticism that we are pandering to the 'rootless cosmopolitan elite' that is educated and wealthy enough to take advantage of the opportunities afforded by European science funding (an argument that flatters scientists and engineers that have long been subservient to the interests of economists, lawyers and politicians, but we digress).

There is, however, another important lesson that can be drawn from these statistics: the ERC itself has confirmed, yet again, its unyielding commitment to its mission to encourage the highest quality research in Europe, wherever it may come from. In the aftermath of the UK's referendum to leave the EU, it was widely predicted that UK-based scientists would have their chances of obtaining European funding curtailed because of the resulting political uncertainty. This, thankfully, appears not to have happened.

Of course, Britain hasn't actually left the EU yet, and there is still enough political uncertainty to worry about a lose-lose scenario in which no deal is reached on the future relationship of the two blocs - the UK's continued participation in the ERC is far from guaranteed. Scholars will naturally worry about losing access to this funding in the future, but the latest figures will be a useful reminder for politicians that there is much more common ground than they care to admit. There is still plenty to fight for.

Published online: 2 May 2018 https://doi.org/10.1038/s41567-018-0147-3 